Eval uat i on of criti cal hemodynamic st at us i nduced by acet azol am de chal I enge i $n$ pat i ent $s$ wi th cer ebr ovascul ar di sease: Assessment of regi onal perfusi on pressure.

\begin{tabular}{|l|l|}
\hline 著者 & $\begin{array}{l}\text { OKAZAMA Hi dehi ko, TSUCH DA Tat sur o, ARAl } \\
\text { Yoshi kazu, MORI Tet suya, KOBAYASH Nasat o, } \\
\text { TANAKA Funm ko, YONEKURA Yoshi har u }\end{array}$ \\
\hline $\begin{array}{l}\text { j our nal or } \\
\text { publ i cat i on ti tl e }\end{array}$ & Journal of Cer ebr al Bl ood Fl ow \& Net abol i sm \\
\hline vol une & 25 \\
\hline number & S1 \\
\hline page r ange & S176- S176 \\
\hline year & 2005- 08 \\
\hline URL & ht t p: //hdl . handl e. net /10098/1198 \\
\hline
\end{tabular}




\title{
Evaluation of critical hemodynamic status induced by acetazolamide challenge in patients with cerebrovascular disease: Assessment of regional perfusion pressure.
}

\author{
${ }^{1}$ Hidehiko Okazawa, ${ }^{2}$ Tatsuro Tsuchida, ${ }^{3}$ Yoshikazu Arai, ${ }^{1}$ Tetsuya Mori, ${ }^{1}$ Masato Kobayashi, \\ ${ }^{1}$ Fumiko Tanaka, ${ }^{1}$ Yoshiharu Yonekura. \\ ${ }^{1}$ Biomedical Imaging Research Center, ${ }^{2}$ Department of Radiology, ${ }^{3}$ Department of Neurosurgery, \\ University of Fukui, Fukui, Japan.
}

Introduction: Autoregulatory mechanism to keep cerebral blood flow (CBF) and perfusion pressure may be impaired in patients with cerebrovascular disease (CVD). To investigate the critical hemodynamic status in the impaired cerebral circulation, changes in regional CBF (rCBF) and arterial-to-capillary blood volume $\left(\mathrm{V}_{0}\right)$ induced by acetazolamide (ACZ) were measured in $\mathrm{CVD}$, as well as changes in hemodynamic parameter defined by $\mathrm{rCBF} / \mathrm{V}_{0}$ ratio, which is expected to be proportional to the regional perfusion pressure.

Method: Thirty-nine patients (mean age $=64.5 \pm 9.3$ y) with unilateral major cerebral arterial occlusive disease underwent $\mathrm{O}-15$ water PET at baseline and $10 \mathrm{~min}$ after ACZ administration. The mean interval between an ischemic event and the PET examination was $5.7 \pm 7.4$ months. Dynamic PET data were acquired to calculate $\mathrm{rCBF}, \mathrm{V}_{0}$ and $\mathrm{rCBF} / \mathrm{V}_{0}$ ratio using the 3-weighted integral method. The hemodynamic parameters in the territories of bilateral middle cerebral arteries were obtained and compared between the 2 hemispheres and 2 conditions.

Results: Following ACZ administration, the group of patients who had a diminished rCBF response in the ipsilateral hemisphere (reduced vasodilatory capacity group $=\mathrm{RVC} ; 22$ patients) showed a significant $V_{0}$ increase in the same region. Thus, the $r C B F / V_{0}$ ratio decreased significantly after ACZ administration in the ipsilateral hemisphere of RVC. This ratio did not change in the contralateral hemisphere of this group nor in the other group with normal vasodilatory capacity (NVC; 17 patients), suggesting that its reduction represented severe hemodynamic impairment and dysfunction of autoregulation for regional perfusion pressure. The significant decrease in $\mathrm{rCBF} / \mathrm{V}_{0}$ ratio was associated with strokes in patients of RVC (Table). Eight patients in RVC (36\%) and 15 in NVC (88\%) had suffered strokes. Twelve patients in RVC (56\%) had a history of TIA, whereas only one in NVC had suffered from TIA (5.9\%). The incidence of past history of stroke and TIA was significantly different between the two groups $(\mathrm{p}<0.005$, Chi-square test).

Conclusion: The lack of rCBF increase after ACZ challenge does not necessarily reflect the exhaustion of vasodilatory capacity in patients with severely impaired cerebral circulation. Decrease in the $\mathrm{rCBF} / \mathrm{V}_{0}$ ratio after $\mathrm{ACZ}$ challenge is presumed to represent altered regional cerebral perfusion pressure reflecting a critical hemodynamic status in patients with CVD because post-ACZ reduction of this ratio was closely associated with hemodynamic deficiency in RVC.

\section{References:}

[1] Okazawa H, et al. $J$ Nucl Med 2003;44:1875-1883.

[2] Ohta S, et al. J Cereb Blood Flow Metab 1996;16:765-780.

Table: Comparing of rCBF/ $\mathrm{V}_{0}$ ratio among different symptoms in RVC and all NVC

\begin{tabular}{|c|c|c|c|}
\hline \multirow[b]{2}{*}{$\mathrm{rCBF} / \mathrm{V}_{0}\left(\mathrm{~min}^{-1}\right)$} & \multicolumn{2}{|c|}{ RVC Ipsilateral } & NVC Ipsilatera \\
\hline & Stroke $(n=8)$ & $\operatorname{TIA}(\mathrm{n}=12)$ & $(n=17)$ \\
\hline Baseline & $25.7 \pm 6.9$ & $24.1 \pm 5.0$ & $20.9 \pm 4.3$ \\
\hline Post-ACZ & $16.9 \pm 4.9^{*}$ & $21.5 \pm 4.5$ & $20.8 \pm 4.7$ \\
\hline \% Change & $-8.8 \pm 5.2^{\dagger}$ & $-2.6 \pm 2.3$ & $-0.1 \pm 2.7$ \\
\hline
\end{tabular}

